\title{
PAVILIUN KEBUDAYAAN BETAWI
}

\author{
Felicia Setiawan', Sidhi Wiguna Teh ${ }^{21}$
}

1)Program Studi S1 Arsitektur, Fakultas Teknik, Universitas Tarumanagara, feliciaasetiawan@gmail.com

2)Program Studi S1 Arsitektur, Fakultas Teknik, Universitas Tarumanagara, sidhi@ft.untar.ac.id

\begin{abstract}
Abstrak
Sebagian besar masyarakat terjebak dengan aktivitas mereka yang monoton, mereka cenderung mencari hiburan yang lebih praktis melalui ponsel pintar, internet atau televisi. Hal tersebut mengurangi esensi dari interaksi sosial yang seharusnya dilakukan. Keberadaan ruang publik sendiri merupakan salah satu faktor yang dapat mendorong terjadinya interaksi sosial. Oleh karena itu penulis melakukan studi literatur, berdasarkan hasil studi penulis dapat menyimpulan bahwa third place dapat menjadi salah satu jembatan interaksi sosial. Third Place menyediakan ruang katalis antara rumah dan tempat kerja, menjadikan third place sebagai tempat singgah yang nyaman. Third Place bukanlah tempat kerja ataupun rumah, melainkan tempat bersantai yang dapat memungkinkan kehidupan komunitas yang terbuka. Pemilihan pusat kebudayaan sebagai third place dikarenakan pusat budaya dapat menuangkan berbagai ekspresi kebutuhan manusia, mimpi dan keinginan. Selain itu, lokasi tapak berada disebelah Taman Ismail Marzuki. Melihat ada beberapa program yang belum dapat diakomodir oleh Taman Ismail Marzuki dan perlunya pengenalan kembali akan nilai-nilai budaya betawi yang mulai pudar di zaman sekarang, mendorongnya diciptakan program - program yang dapat mendukung hal tersebut. Metode perancangan yang digunakan proyek ini adalah metode dis-programming, program yang sifatnya saling mengkontaminasi dengan program lainnya. Letak tapak yang dekat dengan pusat pendidikan dan pusat kebudayaan mendorong terjadinya program yang saling mendukung satu sama lain, disini penulis menggabungkan program yang ada di pusat kebudayaan dengan program pendidikan seperti studio tari, studio musik dan perpustakaan.
\end{abstract}

Kata Kunci: Budaya Betawi; interaksi; katalis; komunitas; sosial

\begin{abstract}
Most people are trapped by their monotonous activities, they tend to look for more practical entertainment through smart phones, the internet or television. That might reduce the real meaning of social interaction. The existence of public space itself is one of many factors that encourgage people to do social interaction. Therefore, as what the author has read in a literature study, that third place able to be one of the bridges of social interaction. Third Place provides a catalyst space between home and work, making the third place a comfortable haven. Third Place is not a place of work or home, but a place to relax that can allow you to have a open community life. The selection of a cultural center as a third place because the cultural center can pour various expressions of human needs, dreams and desires. In addition, the location of the site is next to Taman Ismail Marzuki. Seeing that there are several programs that cannot be accommodated by Taman Ismail Marzuki and the need to reintroduce Betawi cultural values that are starting to fade in the present, encouragge us to create programs that can support this. The design method used by this project is the dis-programming method, a program that is mutually contaminating with other programs, The location is close to the education center and cultural the center which drives both programs to support one another, here the writer combines programs in the cultural center with educational programs such as dance studios, music studios and libraries.
\end{abstract}

\section{Keywords: Betawi Culture; catalyst; community; interaction; social}




\section{PENDAHULUAN}

Sebagian besar masyarakat terjebak dengan aktivitas yang monoton dari kegiatan sehari sehari mereka. Mereka memilih hiburan yang lebih praktis dengan internet, TV atau ponsel pintar. Hal tersebut menjauhkan masyarakat dari komunikasi sosial yang seharusnya. Kebutuhan masyarakat terhadap ruang publik sebagai sarana melakukan aktivitas dengan beragam kegiatan secara bersama - sama diwujudkan melalui interaksi sosial yang diakomodasi dalam ruang publik sehingga terjadi pembelajaran antara manusia satu dengan yang lain, komunitas satu dengan komunitas yang lain, berlangsung terus menerus hingga akhirnya terdapat kesatuan pemahaman bersama bahwa heterogenitas yang ada dalam satu kota merupakan keniscayaan yang harus dijalani dan diterima bersama-sama (Sunaryo dkk), oleh sebab itu ruang publik menjadi ruang kebebasan bagi masyarakat dalam beraktivitas.

Keberadaan ruang publik sendiri merupakan ruang atau lahan umum, tempat masyarakat dapat melakukan kegiatan publik fungsional maupun kegiatan sampingan lainnya, yang dapat mengikat suatu komunitas, baik itu kegiatan sehari-hari ataupun berkala (Carr, 1992). Keberadaan ruang publik menjadi bagian penting bagi masyarakat sebagai salah satu upaya untuk mengatasi terjadinya konflik sosial yang mengarah kepada terciptanya disharmoni dan disintegrasi sosial melalui penyediaan ruang terbuka bersama (open public space) seperti : lapangan olah raga, poliklinik, tempat ibadah, lembaga pendidikan,g pasar/mall/plaza, taman (E, Budiharjo \& Djoko S.:1999).

Third Place memainkan peran penting dalam masyarakat karena mereka menyediakan ruang katalis antara rumah dengan privasinya dan tempat kerja dengan sterilitas, memungkinkan keterlibatan dengan orang asing (Milgram 1977), dan memungkinkan terciptanya jembatan sosial yang membentuk komunitas sosial di masyarakat.

Kedai kopi, bar, dan tempat pangkas rambut adalah beberapa Third Place yang dikatakan oleh Ray Oldenburg (1989). Menurutnya, tempat ini bukan tempat kerja dan juga bukan rumah, Third Place adalah tempat di mana masyarakat setempat berkumpul untuk bersantai dan membahas berbagai topik (misalnya, situasi politik saat ini, kenaikan harga di toko bahan makanan lokal, atau hasil olahraga terbaru). Tempat-tempat ini memungkinkan kehidupan komunitas lebih terbuka. Seperti yang dibahas oleh Oldenburg, third place bersifat low profile, netral, inklusif, mudah diakses, akomodatif, diisi dengan pelanggan tetap, tempat terjadinya percakapan, dan menyenangkan.

Interaksi sosial adalah proses dimana kita bertindak dan bereaksi terhadap orang-orang di sekitar kita. Interaksi sosial termasuk tindakan yang dilakukan orang terhadap satu sama lain dan tanggapan yang mereka berikan sebagai balasannya. Melakukan percakapan singkat dengan seorang teman tampaknya relatif sepele.

Goffman berpendapat bahwa bentuk-bentuk interaksi sosial yang kelihatannya tidak penting ternyata sangat penting dalam sosiologi dan tidak boleh diabaikan. Interaksi sosial mencakup sejumlah besar perilaku sehingga dalam interaksi sosiologi biasanya dibagi menjadi lima kategori: pertukaran, kompetisi, kerja sama, konflik dan paksaan. Di sisi lain, pusat budaya dapat menuangkan berbagai ekspresi kebutuhan manusia, mimpi, keinginan, dan ketakutan sebelum sejarah tertulis.

Ini tercermin di tempat seperti "Pusat Kebudayaan" dimana terdapat keyakinan bahwa jiwa manusia dipersatukan, baik dalam pikiran manusia primitif maupun manusia modern. Claude Levi Strauss meyakini bahwa " Man has always been a symbol of his thought." Pikiran dan fantasi mental yang mencerminkan budaya dan mentalitas orang-orang yang mewakili suatu bangsa. Merancang pusat budaya dapat mendorong semua aspek aspek budaya seni dan mengeksplorasi kepentingan sosial budaya seni. Masyarakat yang terlalu sibuk dengan aktivitas monoton dapat menemukan jati diri mereka melalui budaya bangsa mereka sendiri. 


\section{KAJIAN LITERATUR}

\section{Sharing}

Buku "Sharing Cities: A Case for Truly Smart and Sustainable Cities" oleh Duncan McLaren dan Julian Agyeman, menekankan kata "berbagi". Untuk membangun suatu kota yang berkelanjutan, masyarakat harus terbiasa berbagi. Tentu saja untuk berbagi membutuhkan kepercayaan satu sama lain, kita harus menekankan cara untuk membangun kepercayaan itu. Penulis mengambil contoh dari aplikasi kendaraan online, bagaimana kita dapat mempercayai seseorang yang tidak kita kenal mengemudi untuk kita? Pihak kendaraan online itu membuat penilaian tentang rating setiap pengemudi, semakin tinggi rating artinya semakin bagus pula kinerja pengemudi tersebut.

\section{Space and Place}

Makna Space (ruang) sering disamakan dengan makna Place (tempat). "Ruang" lebih abstrak dari "Place". Sebuah ruang akan menjadi tempat jika kita menganggap ruang tersebut mempunyai arti lebih. Gagasan "ruang" dan "tempat" saling membutuhkan definisi. Dari keamanan dan stabilitas sebuah tempat, kita sadar tentang keterbukaan, kebebasan, dan ancaman ruang, dan sebaliknya. Jika kita menganggap ruang sebagai sesuatu yang memungkinkan pergerakan, maka tempat adalah jeda; setiap jeda dalam pergerakan memungkinkan sebuah ruang menjadi tempat.

\section{Third Place}

Kedai kopi, bar, dan tempat pangkas rambut adalah beberapa Third Place yang dikatakan oleh Ray Oldenburg (1989). Menurutnya, tempat ini bukan tempat kerja dan juga bukan rumah, Third Place adalah tempat di mana masyarakat setempat berkumpul untuk bersantai dan membahas berbagai topik (misalnya, situasi politik saat ini, kenaikan harga di toko bahan makanan lokal, atau hasil olahraga terbaru). Tempat-tempat ini memungkinkan kehidupan komunitas lebih terbuka. Seperti yang dibahas oleh Oldenburg, third place bersifat low profile, netral, inklusif, mudah diakses, akomodatif, diisi dengan pelanggan tetap, tempat terjadinya percakapan, dan menyenangkan.

\section{Karakteristik Third Place}

a. Third Place mewakili pengalaman pribadi

Third Place bersifat personal, tetapu bukan dalam arti individual yang sebenarnya. Pengalaman di third place lah yang merupakan pengalaman personal.

b. Third Place memenuhi kebutuhan individu

Terkadang kebutuhan itu adalah kebutuhan akan interaksi sosial. Terkadang kebutuhan itu kebutuhan untuk berkreatifitas. Di lain waktu, bisa saja kebutuhan akan kesejahteraan pribadi.

c. Third Place membawa kita jauh dari rumah dan tempat kerja, namun mereka sama pentingnya dengan dua hal tersebut.

Third Place merupakan katalis antara dua tempat tersebut, hal ini dapat mendefinisikan siapa kita dan apa yang kita kerjakan.

d. Third Place secara pribadi fungsional bagi kami.

Kita membutuhkan apa yang diberikan pengalaman tempat ketiga kita kepada kita. Pengalaman dari sisi interaksi sosial, pengembangan kreatifitas dan lainnya.

e. 5. Third Place ada saat kita membutuhkannya

Karena jadwal menjadi kurang penting dan menjadi kendala. "secara permintaan", pengalaman tempat ketiga menjadi lebih penting secara proporsional.

\section{Cultural Hub}

Cultural Hub merupakan salah satu sarana yang dapat melestarikan budaya lokal. Fungsi utama Cultural Hub adalah memberikan informasi dan pendidikan seni budaya yang dapat 
memberikan dampak positif dan meningkatkan budi pekerti baik melalui kegiatan kebudayaan. Fungsi Cultural Hub:

a. Merancang dan menyelaras kegiatan pelajar atau masyarakat umum yang berkaitan dengan kebudayaan dan kesenian.

b. Memberikan prasarana untuk memberi peluang mengembangkan bakat dalam aktivitas kesenian dan kebudayaan.

\section{METODE}

Metode perancangan yang digunakan proyek ini adalah metode dis-programming, program yang sifatnya saling mengkontaminasi dengan program lainnya misalnya supermarket dikombinasikan dengan perkantoran, dan lain-lain (I.Makainas, 2011). serta menerapkan behavioural architecture, yaitu arsitektur berwawasan perilaku yang bertujuan untuk menciptakan ruang dan suasana yang sesuai dengan perilaku manusia, lingkungan dan budaya masyarakat (Heimsath,1998).

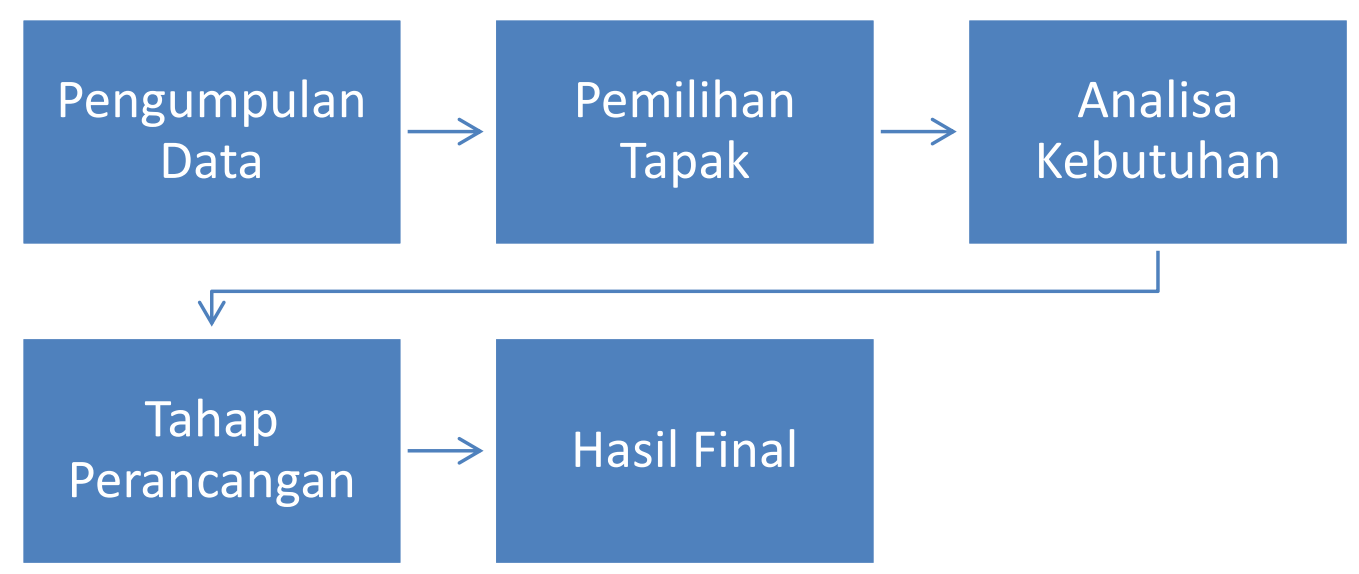

Gambar 1. Tahapan Analisa dan Perancangan Bangunan Sumber: Penulis, 2019

\section{DISKUSI DAN HASIL}

Dari isu third place yang telah kita bahas diatas, penulis mengambil isu budaya betawi sebagai program utama. Program - program nantinya akan didominasi dengan program edukasi. Edukasi disini dapat berupa edukasi tentang kebudayaan betawi ataupun edukasi yang lebih fleksibel dengan penyediaan studio - studio pelatihan sebagai wadah untuk mengembangkan kreativitas masyarakat.

Pemilihan lokasi tapak melalui beberapa kriteria yang dapat mendukung berdirinya "Pusat Kebudayaan" dan kaya akan unsur - unsur Betawi itu sendiri. Berikut merupakan beberapa kriteria tapak:

- Lahan kosong dengan peruntukkan yang sesuai untuk proyek

- Akses ke tapak yang mudah

- Dekat dengan pusat atraksi lainnya

- Dapat dicapai melalui transportasi umum

- Dekat dengan fasilitas Pendidikan 


\section{ANALISA TAPAK}
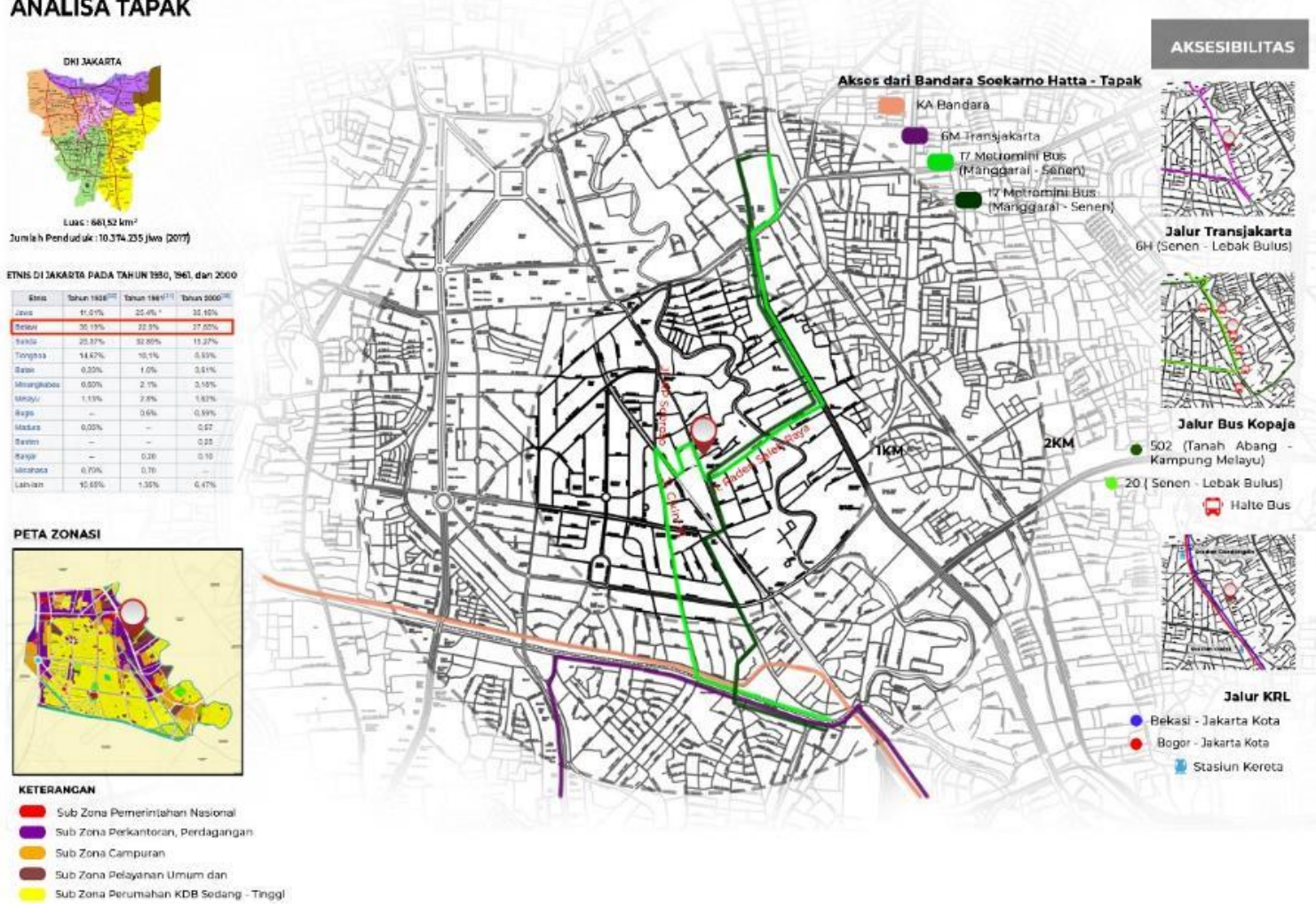

Gambar 2. Analisa Tapak

Sumber: Penulis, 2019

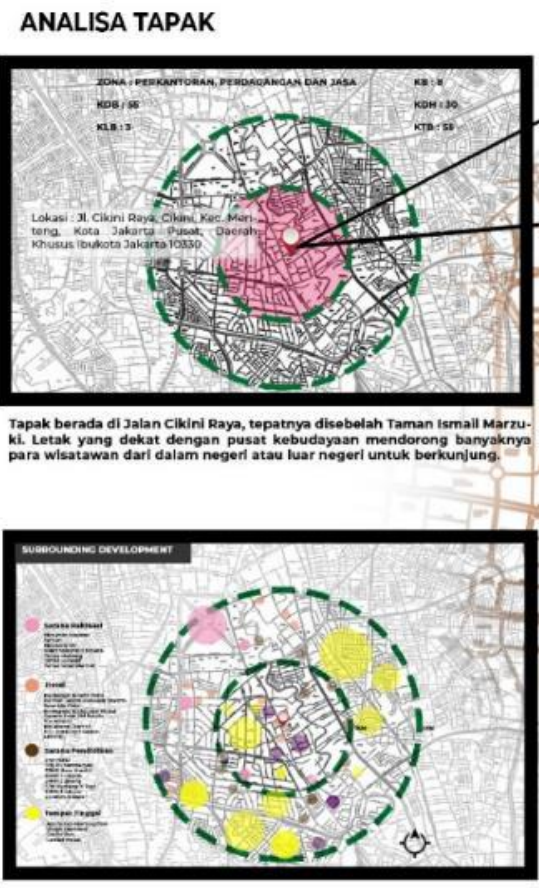

Sokeliling tapak didominasi oloh sarana rokroasi, pendidilikan dan pengina.
pan yang dapat mendorong dibangunnya program berbasis pendidikan

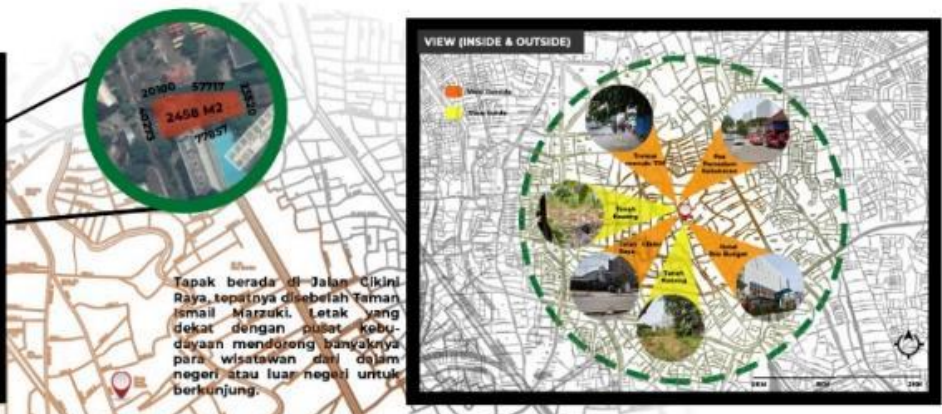

$=160$

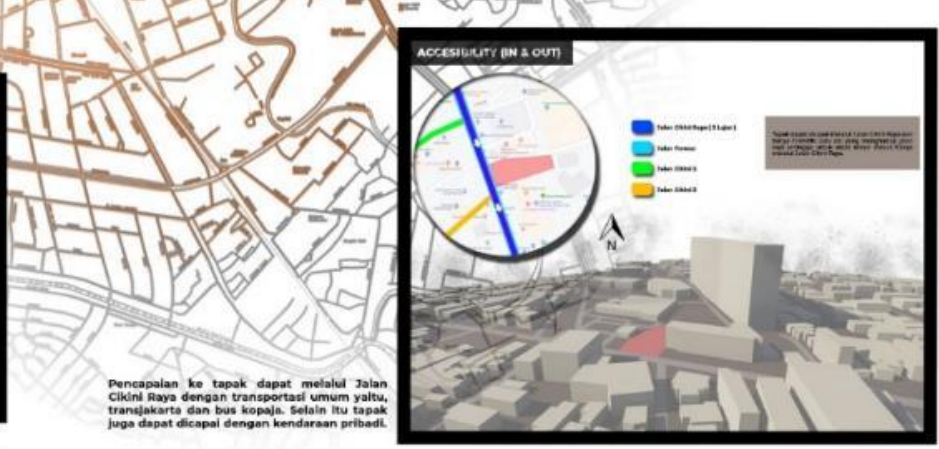

Gambar 3. Analisa Tapak

Sumber: Penulis, 2019 


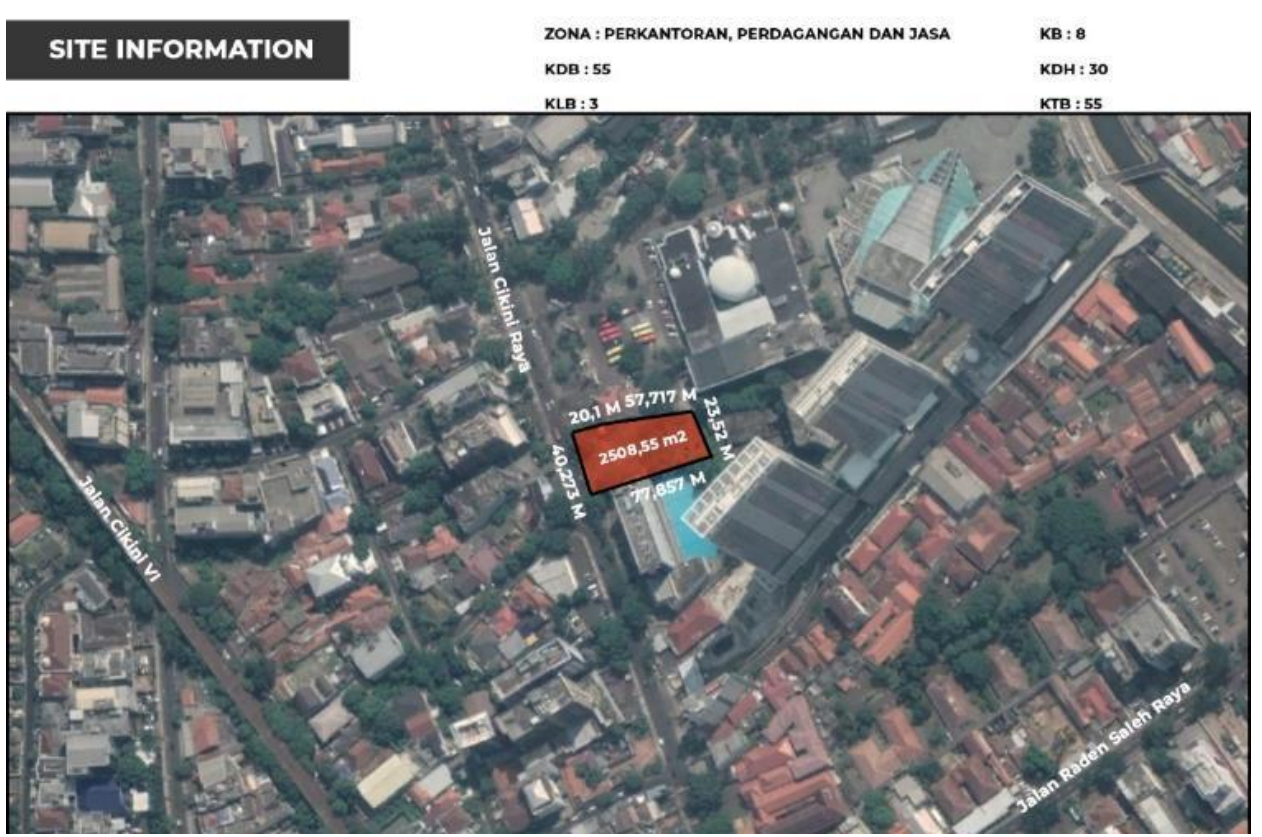

Gambar 4. Informasi Tapak

Sumber: Penulis, 2019

Proyek ini dimaksudkan untuk mengenalkan kembali budaya Betawi yang mulai luntur, Hal itu diwujudkan dari beberapa program dalam bangunan ini yang menyediakan ruang edukasi budaya Betawi. Selain itu, sesuai namanya "paviliun" bangunan ini dimaksudkan untuk menopang Taman Ismail Marzuki yang berada tepat disebelah tapak.

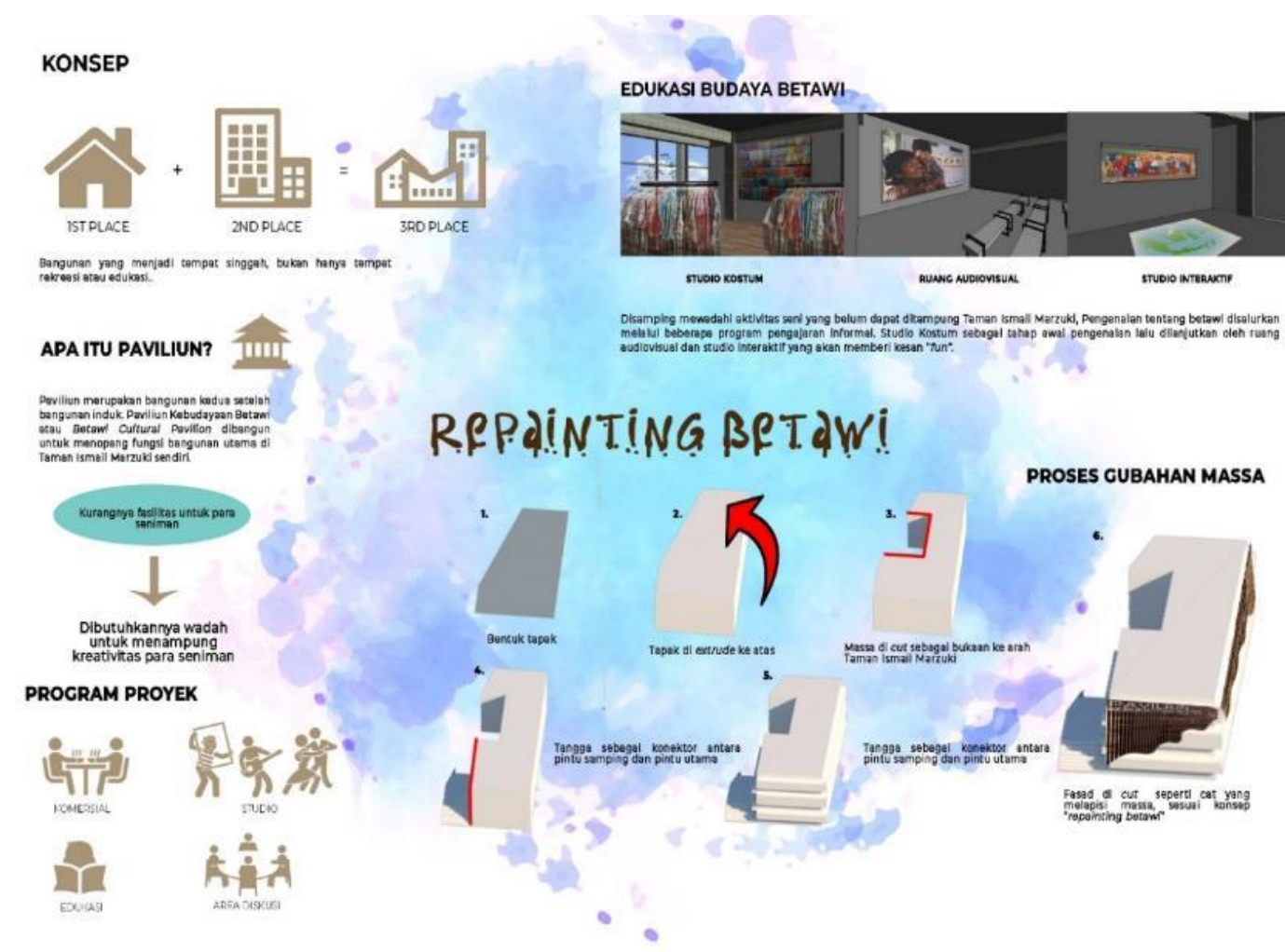

Gambar 5. Konsep dan Proses Gubahan Massa

Sumber: Penulis, 2019 
Proses pembentukan massa dipengaruhi oleh titik akses dan juga pemanfaatan ruang terbukan, selain itu bentuknya yang sederhana dan menyerupai persegi panjang dikarenakan mengikuti urban fabric daerah tersebut. Penggunaan fasad yang seperti gambar diatas merupakan perwujudan dari tema "Repainting Betawi".

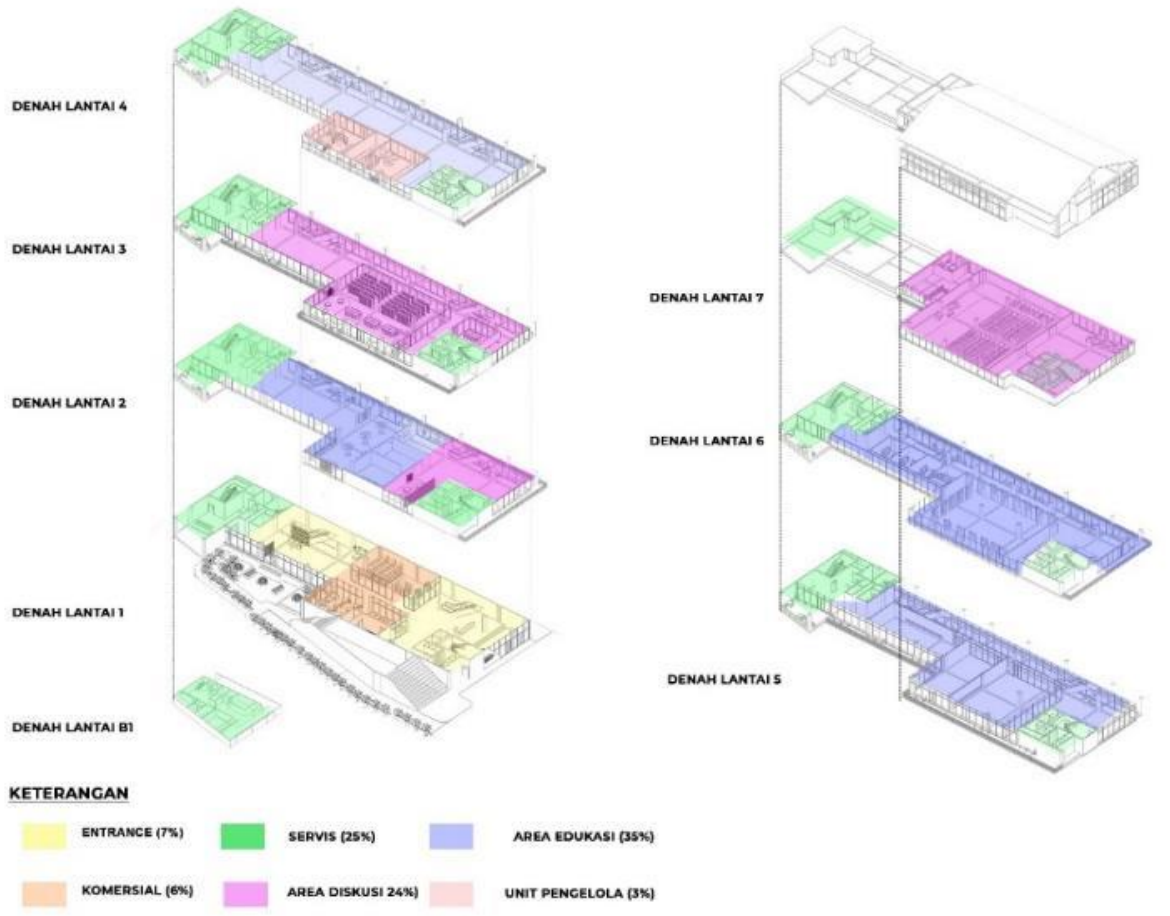

Gambar 6. Programmatik

Sumber: Penulis, 2019

Program bangunan terdiri dari area komersial, edukasi dan diskusi. Pada dasarnya bangunan ini dibuat untuk mewadahi aktivitas masyarakat khususnya dibidang edukasi,yang belum tertampung. Sehingga program ruang dibuat lebih fleksibel agar dapat dinikmati semua kalangan.

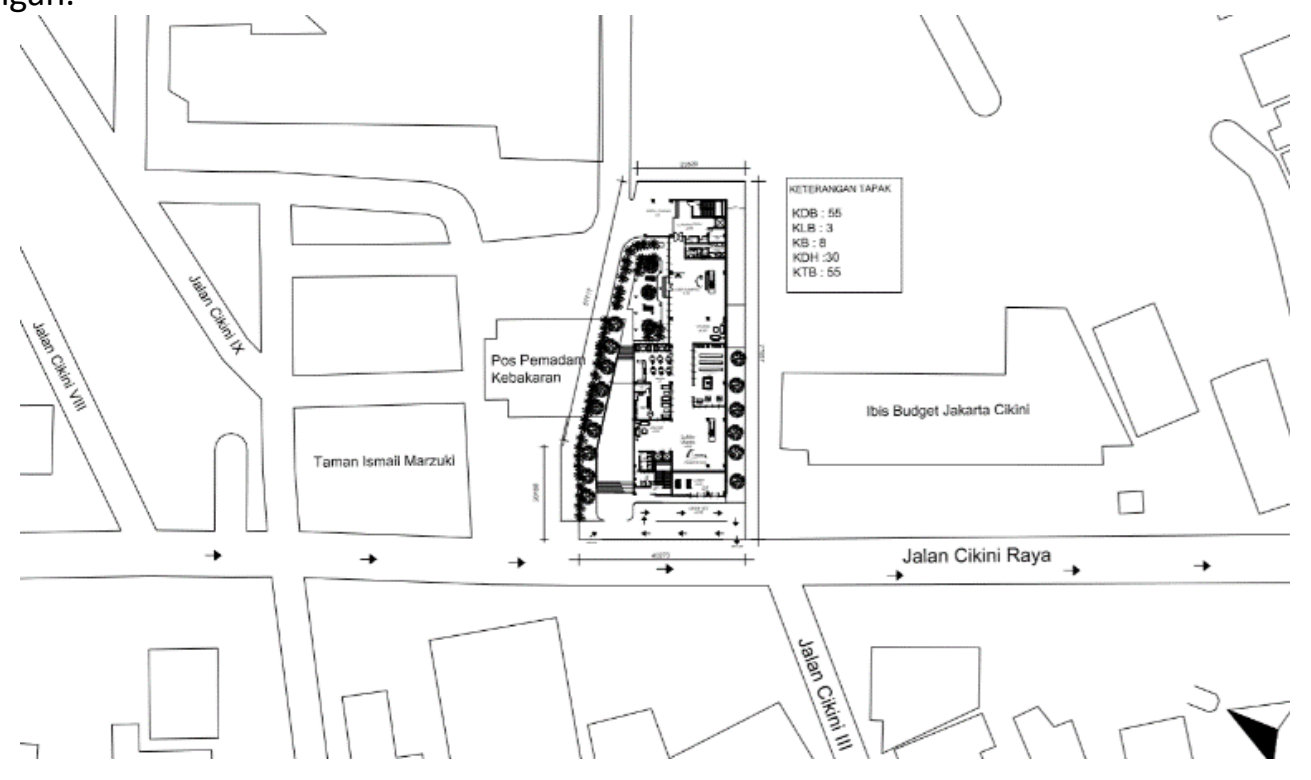

Gambar 7. Site Plan

Sumber: Penulis, 2019 


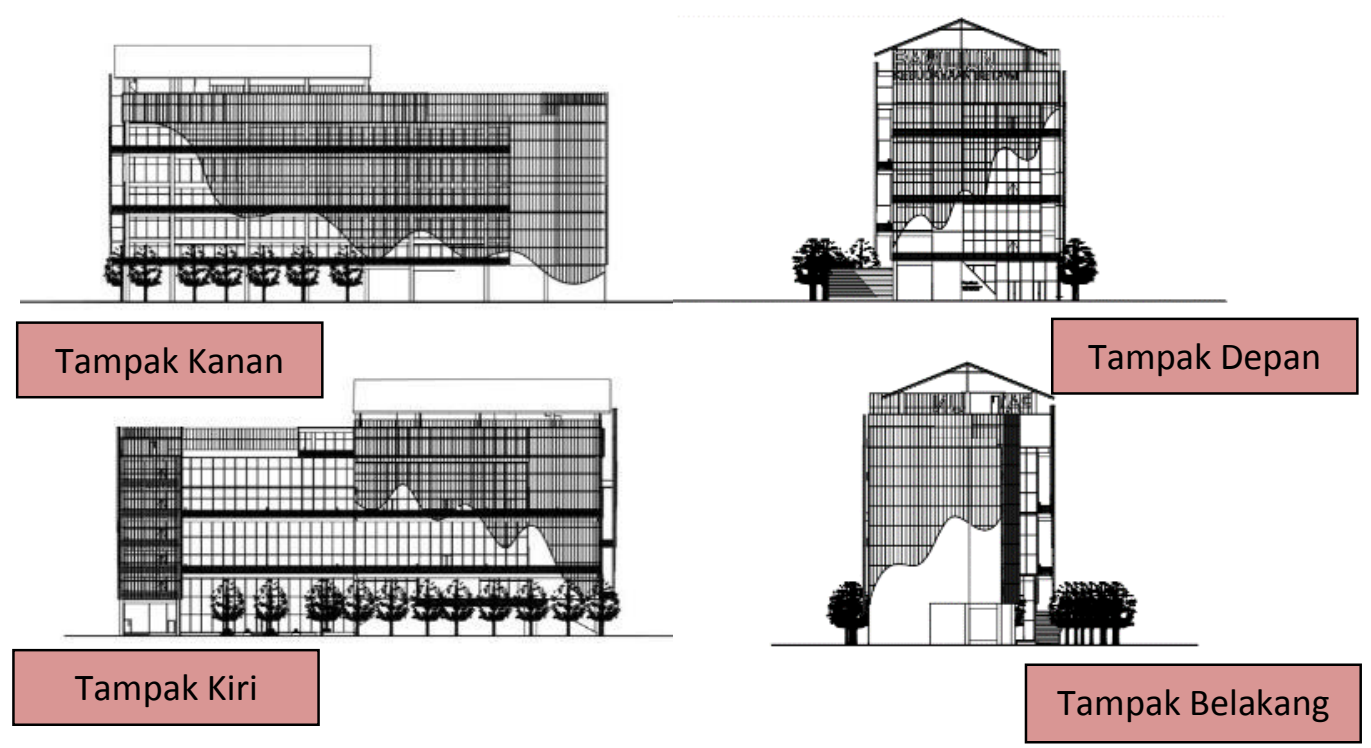

Gambar 8. Tampak Bangunan Sumber: Penulis, 2019

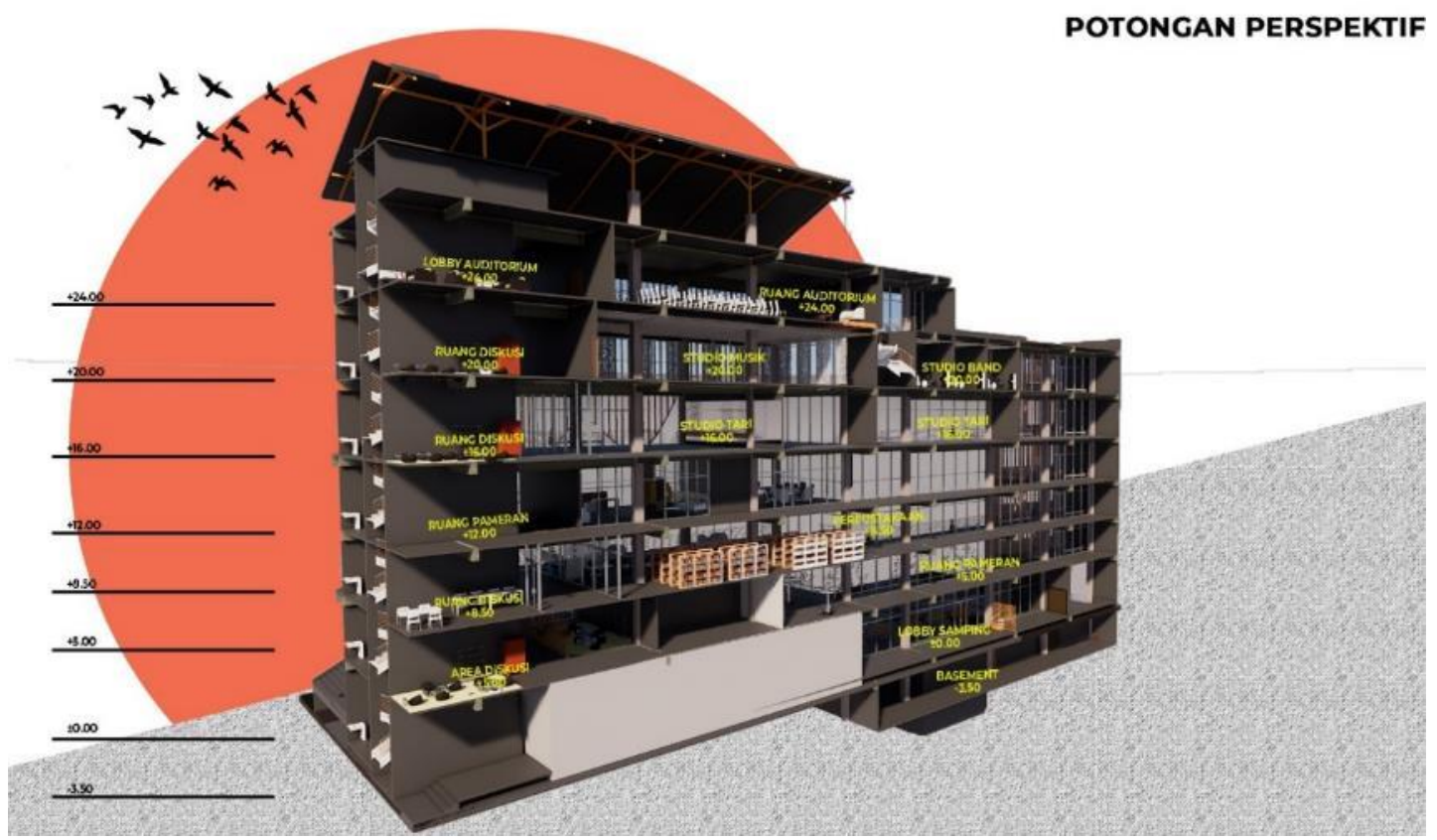

Gambar 9. Potongan Perspektif

Sumber: Penulis, 2019

\section{KESIMPULAN DAN SARAN}

\section{Kesimpulan}

Manusia merupakan makhluk sosial yang membutuhkan interaksi dengan sesamanya di setiap fase kehidupannya namun kota yang ada pada saat ini lebih menawarkan aspek individual dan menjauhkan manusia dari interaksi sosial yang sesungguhnya. Hal tersebut mendorong diperlukannya ruang publik sebagai sarana interaksi sosial. Third Place menyediakan ruang katalis antara rumah dan tempat kerja, yang dapat menciptakan ruang interaksi sosial. Selain memenuhi kebutuhan, third place juga merupakan tempat berkumpul dan kerap dikatakan sebagai "rumah kedua". Cultural Center diharapkan dapat menjadi third place bagi disekitarnya. Kehadiran third place disini berperan sebagai katalis dengan program pusat kebudayaan sebagai jawaban dari isu diatas. Cultural Center dapat berfungsi sebagai ruang interaksi, relaksasi dan edukasi. 


\section{Saran}

Betawi Cultural Pavilion merupakan proyek yang mencakup bidang edukasi dan rekreasi yang menjadi penopang Taman Ismail Marzuki. Hal ini membuat proyek terfokus pada penyediaan wadah bagi masyarakat yang ingin mengembangkan kreatifitasnya. Dilengkapi dengan ruang - ruang studio dan diskusi, kegiatan - kegiatan yang sebelumnya belum tertampung di Taman Ismail Marzuki dapat diwujudkan di proyek ini. Tidak hanya menyediakan wadah, proyek ini juga mengedukasi pengunjung mengenai budaya Betawi melalui beberapa program edukasi yang dibuat secara tidak formal.

Beberapa proses dilakukan penulis mulai dari pengumpulan data, pemilihan tapak, analisa kebutuhan, proses gubah massa hingga hasil perancangan. Hal tersebut dilakukan agar proyek ini terfokus pada apa saja keperluan masyarakat yang belum dapat diwadahi Taman Ismail Marzuki. Pelestarian budaya sangatlah penting di era sekarang, hal tersebut dapat dimulai dari hal - hal kecil. Dalam pembuatan proposal ini tentunya masih banyak kekurangan. Hal ini dikarenakan masih minimnya pengetahuan penulis, untuk itu saya mengharapkan kritik dan saran Bapak/Ibu yang sifatnya membangun guna sebagai bahan evaluasi saya untuk kedepannya agar lebih baik lagi.

\section{REFERENSI}

Adhari, J., Ernawati, J., Santosa, H. Penerapan Konsep Ruang Luar Pada Desain Community Center Di Kota Tangerang Selatan, Universitas Brawijaya, diunduh 10 Juli 2019. < https://media.neliti.com/media/publications/116470-ID-penerapan-konsep-ruang-luarpada-desain.pdf>

Anita, J., Gustya, F., Rahayu, L., Dewi, M. (2019). Kajian Terhadap Ruang Publik Sebagai Sarana Interaksi Warga di Kampung Muararajeun Lama, Bandung, Institut Teknologi Nasional, diunduh $23 \quad$ Agustus $2019 . \quad<$ http://lib.itenas.ac.id/kti/wpcontent/uploads/2013/12/Microsoft-Word-Muara-Rajeun-Juarni-Anita-2012 1.pdf>

Assari A,. Mousavi N. M, Saberi Z. M. B. (2014). P30: Investigation of Sustainability in Road Transportation: A Case Study in Isfahan, Iran. The Neuroscience Journal of Shefaye Khatam, 2(4):80-80.

Budiharjo, E,. \& Djoko S. (1999). Kota Berkelanjutan. Bandung: PT Alumni.

Carr, S. (1992). Public Space. Cambridge: Cambridge University Press

Council NPP. (1992). directory of organizations: Northwest Power Planning Council. USA. Cropanzano R,. Mitchell M. S. ( 2005). Social exchange theory: An interdisciplinary review. Journal of management, 31(6):874-900.

Doharta, N. P. (2016). Cultural Center Sebagai Sarana Konservasi Budaya Sumatera Utara dengan Pendekatan Pada Dalihan Natolu, 80 - 86.

Duncan, M., \& Julian, A. (2015). Sharing Cities: A Case for Truly Smart and Sustainable Cities. Massachusetts, United States: MIT Press.

Goffman E. (1955). On face-work: An analysis of ritual elements in social interaction. Psychiatry, (3):213-231.

Kaelan \& Zubaidi. (2007). Pendidikan Kewarganegaraan.Yogyakarta:Paradigma, Edisi pertama.

Makainas, I,. Mantiri, H. J. (2011), Eksplorasi terhadap Arsitektur Dekonstruksi, Jurnal Media Matrasain Vol.8- No.2,Manado, Fakultas Teknik Arsitektur Universitas Sam Ratulang.

Oldenburg, R. (1997). The Great Good Place. US: Da Capo Press.

Parsaee, M, Parva, M, Karimi, B. Millennials Coming of Age, HBRC Journal, diunduh $<$ https://www.sciencedirect.com/science/article/pii/S1687404814000571>, diakses pada 12 Juli 2019.

Shepherd S,. Wallis M. ( 2004). Drama/theatre/performance. Iran: Routledge.

Tuan, Y.F. (2001). Space and Place : The Perspective of Experience. Minneapolis: University of Minnesota Press. 
